\title{
Can Education Policy Promote Environmental Quality: An Overlapping Generations Model
}

\author{
Fatma Safi ${ }^{1}$, Lobna Ben Hassen ${ }^{2}$ \\ ${ }^{1}$ University of Sfax, \\ Street of Airport, km 4.5, LP 1088, Sfax 3018, Tunisia. \\ E-mail: fatma_safi@yahoo.fr \\ ${ }^{2}$ University of Sfax, \\ Street of Airport, km 4.5, LP 1088, Sfax 3018, Tunisia. \\ E-mail: lobna.benhassen@fsegs.rnu.tn
}

Education is a crucial aspect of the worldwide reaction to climate change. It aids younger generation realize and approach the effect of global warming, inspires changes in their points of view and comportment and aids them adjust to climate change-similar tendency. This paper develops a two-period overlappinggenerations model featuring taxing revenues to finance education and environmental externalities, and studies how an uniform tax rate on both labour income and interests on savings, affects the capital accumulation and the quality of the environment. How does public spending on education affect the environment? We analyze this question by studying the comparative static analysis at the stable steady state equilibrium. Under this framework, results show that public spending on education leads from one hand to capital decreasing and from the other hand has an effect on the environmental quality and this effect depends on the share of human capital in production. In particular, there is a critical proportion of the share of human capital equal to 0,14 above which public spending on education influence negatively the environment, and below which the tax rate reacts inversely with a positive impact on the quality of the environment.

Key words: education; overlapping generations; environment.

JEL Classification: Q20, Q28, Q56, I2.

DOI: $10.17323 / 1813-8691-2021-25-4-628-638$

For citation: Fatma Safi, Lobna Ben Hassen. Can Education Policy Promote Environmental Quality: An Overlapping Generations Model, HSE Economic Journal. 2021; 25(4): 628-638.

Fatma Safi - Department of Economics, Faculty of Economics and Management. Lobna Ben Hassen - Faculty of Economics and Management.

The article was received: 07.05.2021/The article is accepted for publication: 25.11.2021. 


\section{Introduction}

Evidence is expanding that modifications in the climate system are leading to a variety of biophysical and economic effects that are already influencing the society (see [Dell et al., 2009, 2013]). Subsequent consequences are expected to be far greater [IPCC, 2014]. A given amount of climate fluctuations is already locked-in, and there are significant and cascading incertitude with respect to future emissions of greenhouse gases, the eventual modifications in climate, and the eventual environmental and socioeconomic effects.

Because climate modification is viewed as a market failure indicates that it is required to pursue public policies that regulate the inefficient assignation of the market. The extent of the effects, the global dimension of the challenge and the repercussions for coming generations are more than convincing additional factors to call for an institutional architecture to adjust the involvement of private and public players.

In the literature, government is often given a crucial role in preserving the environment, for example, through the application of environmental policies that ensure environmental sustainability directly or resolve environmental collective action issues [Mansbridge, 2014]. Indeed, public expenditure on education can be employed as an indirect involvement to protect the environment, as education offers awareness about the preservation and conservation of the environment, which is necessary for the benefit of the whole of humanity. Education plays a pivotal role in community building that is sensible and conscious towards the environment and its related challenges and issues. Education encourages a global perspective toward the preservation of nature. Appreciation of the environment among individuals and society can generate positive environmental behavioural change.

In the last few years, education is seen as a channel for economic sustainability and consequently for the pollution control. Farzin and Bond (2006) define three channels for a positive link between education level and the enhancement of environmental quality. Firstly, educated society would be more aware of environmental issues and thus would have behaviours and lifestyles towards environmental enhancement. The gaps in information and knowledge about the outcomes of environmental degradation can restrict the public's willingness to pay. Then, educated individuals have access to information and modify their behaviour. Secondly, educated individuals have a greater ability to employ existing means and channels with a view to express their environmental preferences. They may as well get organized in pressure groups or lobbies, to acquire the application of environmental public policies. Thirdly, Farzin and Bond (2006) suppose that educated individuals are "more likely to generate an environmentally progressive civil service, and therefore have democratically-minded public policymakers and organizations that are more receptive to public demands for environmental quality". University educated individuals are presumably to believe in and act on environmental quality (e.g. [Phillips et al., 2018]). The significance for the university is that comprehension the reasons and effects of environment preservation includes not only the full scope of life sciences, physical sciences, engineering and technology, but also economics, social sciences, arts and humanities [Leal Filho et al., 2018].

In defiance of the relative accord on the positive influence of education, several authors consider that education is a component that intensifies pollution. Jorgenson (2003) concludes that education has a positive impact on the ecological footprint. Educated individuals have higher earnings and ability to buy and are encouraged to an excessive consumption of tangible assets. In fact, they wish for a good life purchasing tangible assets without bothering about the outcomes 
of this delight and the ideological model of "consume more to be happier" [Princen et al., 2001] characterized by publicity and the media resulting to a higher consumption of tangible assets. As excessive consumption of assets is an element of overuse of environmental resources, educated individuals give rise to ecological damage. Cortese (2003:16) claims: "Indeed, it is the people coming out of the world's best colleges and universities that are leading us down the current unhealthy, inequitable, and unsustainable path". Whereas university-based scientists pay out for awareness of greenhouse gases and development of renewable energy, they are also concerned about development of the science and technology that is allowing progressing exploitation and usage of fossil fuels. Besides, universities play also a significant role in emissions via their own energy treatment, their investments and the massive travel of their staff and students [Shields, 2019]. Prieur and Bréchet (2013) consider the role played by education on environmental awareness. With constant environmental awareness, the authors demonstrate the existence of a balanced growth path along which environmental quality enhances continually. Nevertheless, with education-led environmental awareness, they show that the economy can reach a steady state or converge to an asymptotic balanced growth path.

Unlike Prieur and Bréchet (2013), we focus particularly on the determination of the impacts of the education expenditures on environmental quality and capital accumulation by studying the comparative static analysis at the stable steady state equilibrium. The objective of this study is to stress on environmental issues and use an overlapping generations (OLG) model to explore the repercussions that public education expenditures can create on the environment. To do so; we suppose an infinite-horizon economy that is populated by individuals living for two periods, youth and old age. Individuals derive utility from both consumption and environmental quality. Even if our modelling setting is correlated with the study by Prieur and Bréchet (2013), who set up, in an environmental framework, an OLG model of public expenditure on education à la Glomm and Ravikumar (1997), it differs from their one in a certain aspect. We assume that the origin of pollution comes from consumption. Instead, the two authors assume that it is derived from physical capital.

The remainder of the paper is organized as follows. Section 2 presents an OLG model and analyzes the properties of this framework. Section 3 considers the competitive equilibrium model. Section 4 studies the steady state. Section 5 concludes the paper.

\section{The Model}

We consider an overlapping generations economy where two generations, young and the old, coexist at every discrete time period $t=1, \ldots,+\infty{ }^{1}$. All individuals are identical within each generation and we assume there is no population growth. Population size is normalized to unity $^{2}$. When young, the individual is endowed with $H_{t}$ units of human capital. As in Glomm and Ravikumar (1997), the stock of knowledge accumulates according to the following constant returns process:

$$
H_{t+1}=G\left(H_{t}, E_{t}\right) .
$$

\footnotetext{
${ }^{1}$ At $t=0$ there exists a unique generation of young individuals.

2 We make abstraction from a free rider problem within a generation in order to focus our attention on intergenerational externalities.
} 
With $E_{t}$ the amount of public expenditures on education at period $t$. The young household is endowed with $H_{t}$ units of human capital. Education is therefore totally financed by public expenditures. For that, the government taxes both labor income and the interests on savings at an uniform tax rate $\tau$. We assume also that there is a payroll tax rate $\sigma$ reserved for social security provision. In her/his youth, the individual supplies knowledge $H_{t}$ to firms for a real wage $\omega_{t} H_{t}$. She/he allocates this wage net of taxes to savings $s_{t}$, maintenance $m_{t}$ and consumption $c_{t}^{1}$ taking as given the tax rate $\tau$ and the payroll tax rate $\sigma^{3}$. When old, the individual supplies her/his savings and her/his social security benefits $b_{t+1}$ to firms and earns the return of savings $R_{t+1} s_{t}$ (with $R_{t+1}=1+(1-\tau) r_{t+1}$ the interest factor $)^{4}$. Her/his income is totally dedicated to the consumption $c_{t+1}^{2}{ }^{5}$. The constraints of the individual over the two periods can therefore be summarized as follows:

$$
\begin{aligned}
& (1-\tau-\sigma) \omega_{t} H_{t}=c_{t}^{1}+s_{t}+m, \\
& c_{t+1}^{2}=\left[1+(1-\tau) r_{t+1}\right] s_{t}+b_{t+1} .
\end{aligned}
$$

In addition, we suppose the government's budget, at the first period, is balanced:

$$
E_{t}=\tau\left(\omega_{t} H_{t}+r_{t} s_{t-1}\right) .
$$

In this framework, we suppose that individuals appreciate the conveniences offered by the environment, especially when old. Individuals are concerned about environmental quality and both the use and non-use values of these conveniences are taken into consideration: for example, agents may be concerned by the surrounding environment (like water and air quality) along with more global environmental challenges (like global warming, natural resources etc.). Following [John, Pecchenino, 1994], the law of motion of environmental quality writes as:

$$
Q_{t+1}=(1-\theta) Q_{t}-\beta\left(c_{t}^{1}+c_{t}^{2}\right)+\gamma m_{t},
$$

where $Q_{t}\left(Q_{t+1}\right)$ is the index of environmental quality in period $t(t+1), 0<\theta<1$ is the natural depreciation rate of the environment, $\beta>0$ is a parameter of consumption externalities, $c_{t}^{1}+c_{t+1}^{2}$ is the aggregate consumption in period $t, m_{t}$ is environmental maintenance, while $\gamma>0$ accounts for its efficiency.

The individual's utility $U$ is derived from consumption and environmental quality in first and second periods, where $U^{\prime}>0$ and $U^{\prime \prime}<0$. The lifetime utility ${ }^{6}$ of an individual born in period $t$ is

$$
U=\ln c_{t}^{1}+\ln c_{t+1}^{2}+\ln Q_{t}+\ln Q_{t+1} .
$$

\footnotetext{
3 The superscript ' 1 ' denotes that an individual is young. The subscript ' $t$ ' means period $t$.

${ }^{4}$ Assuming that this is a small open economy, the gross rate of return on savings is constant over time and taken as given from the point of view of the individual's optimisation problem.

5 The superscript ' 2 ' denotes an older individual. The subscript ' $t+1$ ' means period $t+1$.

6 This specification of the utility function has the advantage of rendering our current analytic objects tractable.
} 


\section{Competitive Equilibrium}

Firms produce the final good $Y_{t}$ with a constant returns to scale technology through skilled labour $L_{t}^{s}$ and physical capital $K_{t}$ :

$$
Y_{t}=F\left(K_{t}, L_{t}^{s}\right) \text {, }
$$

where $L_{t}^{s}$ defines the stock of human capital $H_{t}$ time the amount of unskilled labour $L_{t}$. Given that the production function is homogeneous of degree one, it can be characterised by its intensive form: $f\left(k_{t}\right)$ with $k_{t}=K_{t} / L_{t}^{s}$ the capital-skilled labour ratio ${ }^{7}$. We consider as well that the per capita production function, $f\left(k_{t}\right)$, satisfies the standard neoclassical properties with $f^{\prime}>0$ and $f^{\prime \prime}<0^{8}$. Assume that capital depreciates at the rate $\rho \in(0,1)$ during the production process. As the labour market is competitive, profit maximization in the choice of labour by firms implies that the marginal product of labour must be equated to the real wage.

The optimum choice of labour therefore satisfies $r_{t}=f^{\prime}\left(k_{t}\right)-\rho$

$$
\omega_{t}=f\left(k_{t}\right)-k_{t} f^{\prime}\left(k_{t}\right) .
$$

Similarly, the optimum choice of capital equates the rate of interest to the net marginal product

$$
r_{t}=f^{\prime}\left(k_{t}\right)-\rho,
$$

with $r_{t}$ the real rental rate of capital.

We consider the case of $m>0{ }^{9}$. As John and Pecchenino (1994) illustrate in their paper, if the following generations choose not to spend on the environment, capital accumulation occurs, while the environmental quality reduces continuously in the future as a result of both the accumulation of pollution and the need of maintenance.

By supposing that $s_{t}, m_{t}>0$ and given the assumption on the utility function, the problem admits a solution. Individuals choose $c_{t}^{1}, c_{t+1}^{2}, s_{t}$ and $m_{t}$ to maximize utility (6) subject to the constraints (2), (3) and (5). Thus, the private optimization problem has the first order conditions

$$
\begin{aligned}
& \frac{1}{c_{t}^{1}}=(\gamma+\beta) \frac{1}{Q_{t+1}}, \\
& {\left[1+(1-\tau) r_{t+1}\right] \frac{1}{c_{t+1}^{2}}=\gamma \frac{1}{Q_{t+1}} .}
\end{aligned}
$$

${ }^{7}$ As in [Prieur, Bréchet, 2013].

8 This assumption implies that the productivity of labour is increasing and positive valued.

${ }^{9}$ Notice that there is nothing in the model that prevents the possibility that $m_{t}=0$. For the case $m=0$ see [John, Pecchenino, 1994]. 
Equation (10) states that households choose consumption when they are young, equating the marginal rate of substitution between consumption in youth and environmental quality in old age to the marginal rate of transformation, which stands for $\gamma+\beta$. At the utility maximum, a reduction in utility owing to falling consumption among the young is equal to an enhancement in utility in view of the sum of the extra utility from decreasing consumption externalities, $\beta$, and from increasing the environmental maintenance, $\gamma$.

Equation (11) discloses that a household chooses savings to equate the marginal rate of substitution between consumption in old age and environmental quality in old age to the marginal rate of transformation, which corresponds to $\frac{\gamma}{\left[1+(1-\tau) r_{t+1}\right]}$. At the utility maximum, a decrease in utility owing to falling consumption in old age, which is expressed by $\left[1+(1-\tau) r_{t+1}\right]$, is equal to an increase in utility due to an increase environmental maintenance, $\gamma$.

We assume also that the social security program operates on the pay-as-you-go system. Noting that benefits are paid once an individual has retired, the government budget constraint in period $t+1$ is

$$
\omega_{t+1} \sigma_{t+1}=b_{t+1} \text {. }
$$

The capital market clears when $L_{t}=1$ implying $L_{t}^{s}=H_{t}$ and $K_{t+1}=s_{t}$. Thus;

$$
s_{t}=H_{t+1} k_{t+1} \text {. }
$$

Substituting equations (10), (8), (9), (13) and (12) lagged once into (2) yields

$$
m_{t}=(1-\tau)\left[f\left(k_{t}\right)-k_{t} f^{\prime}\left(k_{t}\right)\right] H_{t}-b_{t} H_{t}-\frac{Q_{t+1}}{(\gamma+\beta)}-H_{t+1} k_{t+1} .
$$

Substituting equations (9) and (13) into (3) yields

$$
c_{t+1}^{2}=\left[1+(1-\tau) f^{\prime}\left(k_{t+1}\right)-\rho\right] H_{t+1} k_{t+1}+b_{t+1} .
$$

Substituting equations (10), (14) and (15) lagged once into (5) leads to

$$
\begin{aligned}
Q_{t+1} & =(1-\theta) Q_{t}-\beta\left[\frac{Q_{t+1}}{(\gamma+\beta)}+\left[1+(1-\tau)\left(f^{\prime}\left(k_{t}\right)-\rho\right)\right] H_{t} k_{t}+b_{t}\right]+ \\
& +\gamma\left[(1-\tau)\left[f\left(k_{t}\right)-k_{t} f^{\prime}\left(k_{t}\right)\right] H_{t}-b_{t} H_{t}-\frac{Q_{t+1}}{(\gamma+\beta)}-H_{t+1} k_{t+1}\right] .
\end{aligned}
$$

In addition, substituting equations (9) and (15) into (11) yields

$$
Q_{t+1}=\gamma H_{t+1} k_{t+1}+\frac{\gamma b_{t+1}}{\left[1+(1-\tau) f^{\prime}\left(k_{t+1}\right)-\rho\right]} .
$$

Equations (16) and (17) depict the law of motion for the environment. 


\section{Steady State}

Since all nominal variables and per-capita variables are constant in the steady state, time subscripts are eliminated. Let $\bar{k}$ and $\bar{Q}$ denote steady state values. Equations (16) and (17) can be rewritten as

$$
\begin{aligned}
(1+\theta) \bar{Q}= & -\beta\left[\left[1+(1-\tau)\left(f^{\prime}(\bar{k})-\rho\right)\right] \bar{H} \bar{k}+b\right]+ \\
& +\gamma\left[(1-\tau)\left[f(\bar{k})-\bar{k} f^{\prime}(\bar{k})\right] \bar{H}-b \bar{H}-\bar{H} \bar{k}\right], \\
\bar{Q}=\gamma \bar{H} \bar{k}+ & \frac{\gamma b}{\left[1+(1-\tau) f^{\prime}(\bar{k})-\rho\right]} .
\end{aligned}
$$

The following proposition characterizes the comparative static behaviour of the steady state of this model.

First, to prove the stability of the steady-state equilibrium, we rewrite equations (16) and (17) as

$$
\begin{aligned}
& 2 Q_{t+1}-(1-\theta) Q_{t}+\beta\left[\left[1+(1-\tau)\left(f^{\prime}\left(k_{t}\right)-\rho\right)\right] H_{t} k_{t}+b_{t}\right]- \\
& -\gamma\left[(1-\tau)\left[f\left(k_{t}\right)-k_{t} f^{\prime}\left(k_{t}\right)\right] H_{t}-b_{t} H_{t}-H_{t+1} k_{t+1}\right]=0, \\
& Q_{t+1}=\gamma H_{t+1} k_{t+1}+\frac{\gamma b_{t+1}}{\left[1+(1-\tau) f^{\prime}\left(k_{t+1}\right)-\rho\right]}
\end{aligned}
$$

where $f^{\prime}(k)>\rho$. Since (A.2) implicitly defines $Q_{t+1}$ as a function of $k_{t+1}$ only, rewrite it as

$$
Q_{t+1}=\varphi\left(k_{t+1}\right) .
$$

It is easy to confirm that $\varphi^{\prime}()>$.0 ; namely, a higher capital stock is associated with higher environmental quality. Let $\bar{k}$ and $\bar{Q}$ denote steady state values. The law of motion for the environment (A.1), in steady state, can be rewritten as

$$
\bar{Q}=\frac{1}{(1+\theta)}\left\{\begin{array}{l}
-\beta\left[\left[1+(1-\tau)\left(f^{\prime}(\bar{k})-\rho\right)\right] \bar{H} \bar{k}+b\right] \\
+\gamma\left[(1-\tau)\left[f(\bar{k})-\bar{k} f^{\prime}(\bar{k})\right] \bar{H}-b \bar{H}-\bar{H} \bar{k}\right]
\end{array}\right\}=\psi(\bar{k}) .
$$

The first-order condition (A.3) is, in steady state, $\bar{Q}=\varphi(\bar{k})$.

To derive the stable condition, substitute (A.3) and (A.3) lagged once into (A.1) to obtain the following first-order nonlinear difference equation in $k$ :

$$
\begin{aligned}
& 2 \varphi\left(k_{t+1}\right)-(1-\theta) \varphi\left(k_{t}\right)+\beta\left[\left[1+(1-\tau)\left(f^{\prime}\left(k_{t}\right)-\rho\right)\right] H_{t} k_{t}+b_{t}\right]- \\
& -\gamma\left[(1-\tau)\left[f\left(k_{t}\right)-k_{t} f^{\prime}\left(k_{t}\right)\right] H_{t}-b_{t} H_{t}-H_{t+1} k_{t+1}\right]=0 .
\end{aligned}
$$



to obtain

We can derive the stable condition by linearizing (A.4) around the steady state value $\bar{k}$

$$
K_{t+1}-\bar{K}=\left[\frac{(1-\theta) \varphi^{\prime}-(\gamma \bar{H}+\beta)(1-\tau) \bar{k} f^{\prime \prime}(\bar{k})-\beta\left[1+(1-\tau)\left(f^{\prime}(\bar{k})-\rho\right)\right]}{2 \varphi^{\prime}-\gamma}\right]\left(K_{t}-\bar{K}\right)
$$

The coefficient on the right-hand side of (A.5) is less than one if and only if $\varphi^{\prime}(\bar{k})>\psi^{\prime}(\bar{k})$. Second, totally differentiating (18) and (19), taking $\theta, \beta, \gamma, \rho$ and $\bar{H}$ as given, we have

$$
\left[\begin{array}{ll}
\lambda_{1} & \lambda_{2} \\
\lambda_{3} & \lambda_{4}
\end{array}\right]\left[\begin{array}{l}
d \bar{Q} \\
d \bar{k}
\end{array}\right]=\left[\begin{array}{l}
\lambda_{5} \\
\lambda_{6}
\end{array}\right] d \tau
$$

Let

$$
\begin{aligned}
& \lambda_{1}=(1+\theta), \\
& \lambda_{2}=(1-\tau)(\gamma \bar{H}+\beta) \bar{k} f^{\prime \prime}(\bar{k})+\beta(1-\tau)\left(f^{\prime}(\bar{k})-\rho\right)+\gamma \bar{H}, \\
& \lambda_{3}=1+(1-\tau)\left(f^{\prime}(\bar{k})-\rho\right), \\
& \lambda_{4}=-\gamma \bar{H}\left[1+(1-\tau)\left(f^{\prime}(\bar{k})-\rho\right)\right]+\left(1-\tau(\bar{Q}-\gamma \bar{H} \bar{k}) f^{\prime \prime}(\bar{k})\right), \\
& \lambda_{5}=\beta\left(f^{\prime}(\bar{k})-\rho\right)-\gamma\left[f(\bar{k})-\bar{k} f^{\prime}(\bar{k})\right] \bar{H}, \\
& \lambda_{6}=(\bar{Q}-\gamma \bar{H} \bar{k})\left(f^{\prime}(\bar{k})-\rho\right) \text { where } \bar{Q}-\gamma \overline{H k}=\frac{\gamma b}{\left[1+(1-\tau)\left(f^{\prime}(\bar{k})-\rho\right)\right]} .
\end{aligned}
$$

Let $|D|=\lambda_{1} \lambda_{4}-\lambda_{3} \lambda_{2}$ denotes the determinant, where $\lambda_{4}<0$. Thus, $\lambda_{2} \geq 0$ is sufficient for $|D|<0$. Condition $\lambda_{2} \geq 0$ is not very restrictive.

Proposition: Under the stable condition, societies with higher values of tax rate (higher $\tau$ ) accumulate less capital. As regards the environmental quality, the tax rate has an effect on it which depends on the share of human capital in production $(1-\alpha)$.

Proof: The effects of an increase in the tax rate on capital accumulation and environmental quality can be written as

$$
\begin{aligned}
& \frac{\partial \bar{k}}{\partial \tau}=\frac{1}{|D|}\left\{\lambda_{1} \lambda_{6}-\lambda_{3} \lambda_{5}\right\}<0, \\
& \frac{\partial \bar{Q}}{\partial \tau}=\frac{1}{|D|}\left\{\lambda_{4} \lambda_{5}-\lambda_{2} \lambda_{6}\right\} .
\end{aligned}
$$

The sign of $\frac{\partial \bar{Q}}{\partial \tau}$ is ambiguous. For this reason, we will detect the impact of $\tau$ on $\bar{Q}$ by referring to the figure below. Let us consider $f(k)=A k^{\alpha}, \alpha \in(0,1)$. 


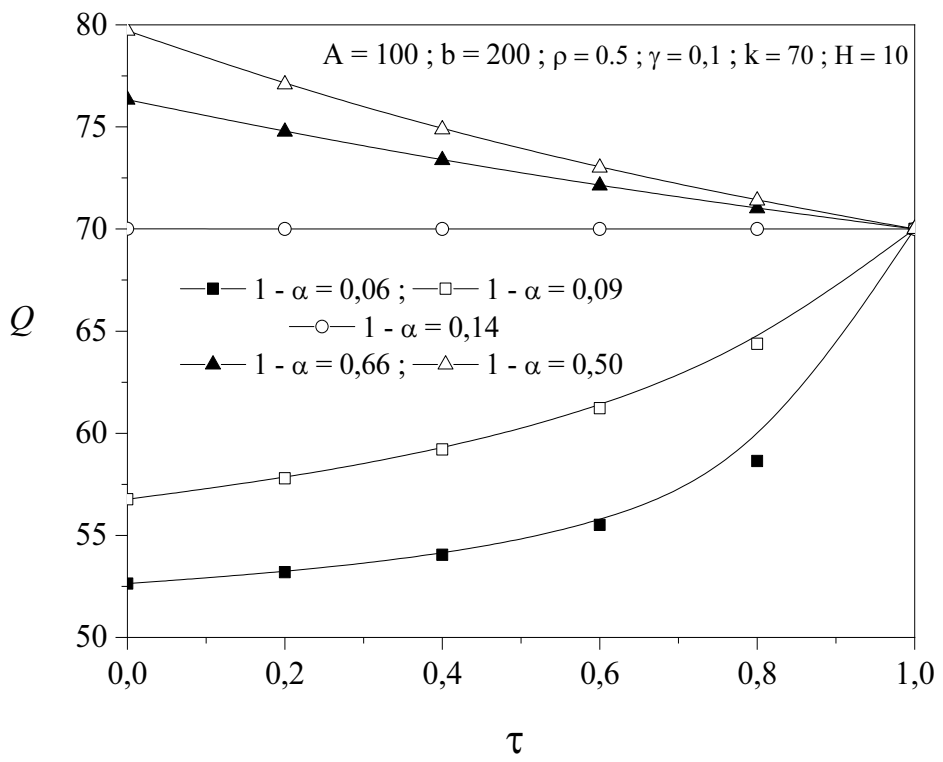

Fig. 1. Effect of tax rate on environmental quality

Fig. 1 represents the evolution of the economic variable $Q$ as a function of the parameter $\tau$ for different proportions $1-\alpha$ in the [zero-unit] row. In the case where $1-\alpha=0,14$, the parameter $\tau$ has no influence on $Q$ whose evolution remains permanent $Q=70$. Below $1-\alpha=0,14, Q$ progressively evolves to reach its maximum value when $\tau$ tends to 1 . Above $1-\alpha=0,14$, an inverse behavior of $Q$ is observed which decreases slightly to reach its minimum value when $\tau$ tends to 1 . We then see that the behavior of $Q$ strongly depends on the numerical value of the $1-\alpha$ proportion when $\tau<1$. For high values of $\tau$ ( $\tau$ tends towards 1 ), the influence of $\tau$ on $Q$ is weak or even non-existent when $\tau=1$. We can thus conclude that $1-\alpha=0,14$ is considered as a critical proportion above which $\tau$ has a negative influence on $Q$, and below which $\tau$ reacts inversely with a positive effect on the variable $Q$ and this for $0 \leq \tau<1$.

The economic intuition behind our result is that: when $1-\alpha=0,14$, a higher tax rate indicates that the young agent has fewer resources to dedicate to consumption. If consumption is reduced, then the negative impact of consumption on the environment is decreased and the environmental quality is higher. On the other side, the old agent consumes less since the returns on savings decrease which implies a positive effect on the environment. When $1-\alpha=0,14$, an increase in the tax rate leads to a decrease in maintenance effort which worsens the environmental quality. On the other hand, a higher tax rate enhances the government revenue and promotes public expenditures on education. More human capital implies more production and more income distributed to individuals. This has a negative effect on the environment. When $1-\alpha=0,14$, the good and bad effects on the environment cancel each other for every $\tau$ and the environmental 
quality remains constant. As for capital accumulation, a higher tax leads to its decline due to the decrease in savings.

\section{Conclusion}

Education is entirely financed by public expenditures. In that purpose the government taxes both labor income and the interests on savings at an uniform tax rate. Prieur and Béchet (2013) state that raising the tax decreases physical capital and environmental quality if and only if the tax is initially below the share of human capital in production. When the tax is above the share of human capital, then the impact of increasing the tax on physical capital and the environment is unclear. This paper revisits this topic by considering the competitive equilibrium model developed by John and Pecchenino (1994). The main finding of this paper is that public spending on education leads to capital decreasing and has an effect on the environmental quality and this effect depends on the value of share of human capital in production.

This paper's model is admittedly highly stylized and abstracts from many possible complications or generalizations. Nevertheless, we hope that this exposition will shed light on an interesting issue - how public education expenditures affect environmental quality.

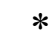

\section{References}

Cortese A. (2003) The Critical Role of Higher Education in Creating a Sustainable Future. Planning for Higher Education, 31, 3, pp. 15-22.

Dell M., Jones B.F., Olken B.A. (2009) Temperature and Income: Reconciling New Cross-sectional and Panel Estimates. The American Economic Review, 99, 2, pp. 198-204.

Dell M., Jones B.F., Olken B.A. (2013) What Do We Learn from the Weather? The New Climateeconomy Literature. NBER (National Bureau of Economic Research) Working Paper Series, no. 19578. Cambridge, Massachusetts: NBER.

Farzin Y.H., Bond C.A. (2006) Democracy and Environmental Quality. Journal of Development Economics, 81, 1, pp. 213-235.

Glomm G., Ravikumar B. (1997) Productive Government Expenditures and Long Run Growth. Journal of Economic Dynamics and Control, 21, pp. 183-204.

IPCC (2014) Climate Change 2014: Impacts, Adaptation, and Vulnerability. Part A: Global and Sectoral Aspects, Contribution of Working Group II to the Fifth Assessment Report of the Intergovernmental Panel on Climate Change (eds. C.B. Field, V.R. Barros, D.J. Dokken, K.J. Mach, M.D. Mastrandrea, T.E. Bilir, M. Chatterjee, K.L. Ebi, Y.O. Estrada, R.C. Genova, B. Girma, E.S. Kissel, A.N. Levy, S. MacCracken, P.R. Mastrandrea, L.L. White). Cambridge, United Kingdom and New York, NY, USA: Cambridge University Press.

John A., Pecchenino R. (1994) An Overlapping Generations Model of Growth and the Environment. The Economic Journal, 104, 427, pp. 1393-1410.

Jorgenson A.K. (2003) Consumption and Environmental Degradation: A Cross-national Analysis of the Ecological Footprint. Social Problems, 50, 3, pp. 374-394. 
Leal Filho W., Morgan E.A., Godoy E.S., Azeiteiro U.M., Bacelar-Nicolau P., Veiga Ávila L., MacLean C., Hugé J. (2018) Implementing Climate Change Research at Universities: Barriers, Potential and Actions. Journal of Cleaner Production, 170, pp. 269-277.

Mansbridge J. (2014) The Role of the State in Governing the Commons. Environmental Science \& Policy, 36, pp. 8-10.

Phillips D., Curtice J., Phillips M., Perry J. (2018) British Social Attitudes: The 35th report. London: The National Centre for Social Research. Available at: www.bsa.natcen.ac.uk/media/39284/bsa35_fullreport.pdf

Prieur F., Bréchet T. (2013) Can Education Be Good for Both Growth and the Environment? Macroeconomic Dynamics, 17, 5, pp. 1135-1157.

Princen T. (2001) Consumption and its Externalities: Where Economy Meets Ecology. Global Environmental Politics, 1, 3, pp. 11-30.

Shields R. (2019) The Sustainability of International Higher Education: Student Mobility and Global Climate Change. Journal of Cleaner Production, 217, pp. 594-602. 